\title{
Del soplo a la voz: la escritura como emancipa- ción de la hegemonía en El libro vacio de Josefina Vicens
}

\author{
From the breath to the voice: writing as a hegemonic \\ emancipation in El libro vacio by Josefina Vicens
}

Alexis GonzÁlez Cruz

ORCID: 0000-0001-5808-3281

Universidad Iberoamericana, México

alexis.gonzalezcz@gmail.com

\section{Resumen:}

El presente artículo analiza la novela El libro vacio de la escritora mexicana Josefina Vicens a la luz de la propuesta teórica sobre la escritura que Hélène Cixous plantea en dos ensayos: La llegada a la escritura y La risa de la medusa. Se sostiene que su protagonista, José García, desarrolla una voz-escritura, motivada por un soplo corporal, que se resiste a una representación falologocéntrica a través de la contraposición entre la intencionalidad del narrador y la configuración textual. Se propone entonces, que, mediante la lógica femenina del gasto y el goce, la novela plantea un registro de masculinidad diferente al hegemónico.

Palabras clave:

escritura, hegemonía, masculinidad, literatura latinoamericana, Josefina Vicens, Hélène Cixous.

Abstract:

This article analyzes Josefina Vicens's novel El libro vacio in the light of the theoretical proposal on writing that Hélène Cixous 
raises in two essays: Coming to Writing and The Laugh of Meduse. In the novel, José García develops a voice of writing, motivated by a bodily breath, that resists a phallologocentric representation through the contrast between the narrator's intentionality and textual configuration. It is proposed, then, that through the feminine logic of expenditure and enjoyment, the novel presents a register of masculinity different from the hegemonic one.

Key words:

writing, hegemony, masculinity, Latin American literature, Josefina Vicens, Hélène Cixous.

DOI: https://doi.org/10.36798/critlit.v0i23.370

Recibido: 16 de diciembre de 2020

Aceptado: 28 de abril de 2021

\section{Introducción}

La escritura supone una transgresión desde muchas aristas. El uso de una herramienta intangible como el lenguaje incita la sospecha e implica la ruptura de edictos como la utilidad, la productividad, la identidad, entre otros. Bajo este tenor, a lo largo de los siglos en que la escritura ha acompañado al ser humano, ¿cuántas mujeres han sido señaladas por escribir?, ¿a cuántas se les ha prohibido? Mujeres como Sor Juana, Mary Shelley o Amantine Aurore Dupin, mejor conocida como George Sand, tuvieron que disfrazar su pluma para que los estigmas del mundo literario no recayeran en ellas.

Sin embargo, ¿qué sucede con las escritoras cuyo disfraz no solo pretende insertarse en esferas dominadas por hombres? ¿Qué pasa con las identidades que se salen del molde? Josefina Vicens dejó una huella imborrable en la historia de la literatura mexicana no solo por su incansable participación en la vida cultural del país, sino por su aguda personalidad que acompañó a su obra literaria, una que de principio a fin criticó los roles sociales, los procesos creativos y la idiosincrasia del mexicano. La "Peque Vicens", como la llamaban sus amigos, representaba todo lo contrario a su apodo: 
una mujer de baja estatura que escribía sobre toros, sobre la irónica realidad política de su tiempo y sobre hombres que se escurrían, a veces involuntariamente, de la estrecha y asfixiante pauta de masculinidad predominante.

El paralelismo entre Vicens y sus personajes ya ha sido planteado con anterioridad ${ }^{1}$ expresado en la disyuntiva de vivir o escribir, pues Josefina Vicens, a pesar de contar con solo dos novelas, El libro vacio (1958) y Los años falsos (1982), un cuento titulado "Petrita" y algunos poemas, cuenta con una amplia trayectoria ${ }^{2}$ en ámbitos tan diversos como la crónica taurina, bajo el seudónimo de Pepe Faroles; la sátira política, bajo la identidad textual de Diógenes García; la política, en la Secretaría de Acción Femenil de la Confederación Nacional Campesina; y el guionismo. ${ }^{3}$ Según Aline Petterson, "cuando la acosaban con la pregunta de su escasa producción literaria, ella decía que estaba ocupada viviendo. Y lo hizo de tantas formas que se acaba por perdonarle la omisión de otros libros importantes, ahogados en el tintero" (25). La incógnita de su corta obra acompañará siempre a una autora que fundó a través de su escritura y, de manera silenciosa, tal como José García, "una cofradía secreta, por no revelar una pasión escondida... que habrán descubierto una pluma extraordinaria en el panorama de las letras mexicanas" (Gordon 12).

${ }^{1}$ Ute Seydel profundiza la dimensión de espejo identitario entre Josefina Vicens y sus personajes, especialmente en Los años falsos.

${ }^{2}$ En Josefina Vicens: Un vacío siempre lleno, compilado por Maricruz Castro y Aline Petterson, y publicado por el Tecnológico de Monterrey, Campus Toluca en colaboración con el FONCA, se ofrece un amplio panorama de la vida de la autora tabasqueña; textos como los de las propias compiladoras y otras críticas, abordan las "diferentes pasiones de la Peque Vicens".

${ }^{3}$ Para conocer más de la faceta de guionista de Vicens y su relación con su obra literaria, puede consultarse el apartado "Del oficio a la pasión: guiones cinematográficos", donde textos pertenecientes a críticas y críticos como María Rosa Palazón Mayoral, Víctor Manuel Medina Cervantes, Norma Lojero, entre otros, hablan de guiones como Los perros de Dios y Aviso de ocasión. Todos ellos presentes en Josefina Vicens: Un clásico por descubrir, coordinado por Ana Rosa Domenella y Norma Lojero, y publicado por la Universidad Autónoma Metropolitana en 2017. 
Las novelas de Josefina Vicens han sido estudiadas desde tres ejes de investigación principales: el primero responde al tema del existencialismo, ${ }^{4}$ la nada y la vida urbana ${ }^{5}$; el segundo se sitúa alrededor de Vicens y su lugar en la literatura mexicana según los temas que trató en sus textos y las relaciones que tenía con otras figuras del medio literario ${ }^{6}$ como Juan Rulfo, Octavio Paz y los Contemporáneos. Es importante anotar que, de igual modo, se ha estudiado El libro vacio como iniciador de una corriente metaficcional ${ }^{7}$ y metaliteraria que se extiende hasta novelas posteriores como Farabeuf (1965) de Salvador Elizondo, Morirás lejos (1967) de José Emilio Pacheco o Cambio de piel (1967) de Carlos Fuentes.

Como tercer eje de investigación, tanto El libro vacio como Los años falsos gozan de un amplio análisis desde los estudios de género. Numerosos textos académicos plantean a sus protagonistas, José García y Luis Alfonso, respectivamente, como mecanismos de subversión o de cuestionamiento de la masculinidad. En dichas investigaciones se estudia a los personajes femeninos y a los masculinos desde su discursividad y su relación con los roles de género. ${ }^{8}$

${ }^{4} \mathrm{El}$ trabajo de Angélica Tornero "Existencialismo y literatura. El libro vacío de Josefina Vicens" anota las perspectivas de la novela desde la corriente filosófica del existencialismo.

${ }^{5}$ Artículos como "La nada y sus contextos: la ausencia de la obra en El libro vacio de Josefina Vicens" de Sara Pollack, "Josefina Vicens: el derecho al silencio" de Raquel Mosqueda Rivera o la tesis de licenciatura de Fernando Trinidad Reves López titulada Novela y existencia en El libro vacio de Josefina Vicens profundizan en dicho análisis.

${ }^{6}$ Los textos, "Josefina Vicens, una voluntad de autonomía" de Gabriela Cano y "Josefina rebautizada" de Adriana González Mateos proveen aproximaciones autobiográficas; sin olvidar la biografía publicada en 2017 por la Universidad Autónoma Metropolitana y resultado de una exhaustiva investigación por parte de Norma Lojero: Josefina Vicens. Una vida a contracorriente... Sumamente apasionada.

${ }^{7}$ El ensayo "Narrador equisciente. La mujer objeto. El libro vacio y Los años falsos de Josefina Vicens" de Ana Josefina Martínez Rodríguez profundiza el juego metanarrativo en las novelas de Vicens.

${ }^{8}$ La tesis de Maestría en Humanidades de Isabel Lincoln Strange Reséndiz, bajo la dirección de la Dra. Ana Rosa Domenella, titulada "La masculinidad como producción discursiva y la feminidad como silencio en El libro vacio y Los 
También se ha analizado la obra de la narradora y su diálogo con diferentes corrientes teóricas del feminismo, ${ }^{9}$ como el concepto de tecnologías de género de Teresa de Lauretis, o en el caso particular del feminismo de la diferencia francés entre quienes figuran Hélène Cixous, Luce Irigaray y Julia Kristeva, el cual cuestiona el sistema falologocéntrico cimentado en la diferencia sexual entre los cuerpos a los que se les otorga una categoría de género.

El presente artículo se inserta en este eje de los estudios de género y entabla un diálogo entre El libro vacio y la propuesta teórica sobre la escritura de la filósofa argelina Hélène Cixous. Se propone entonces que, en El libro vacio de Josefina Vicens, la voz-escritura del protagonista, José García, resiste a la representación masculina a través de la oposición entre la intencionalidad del narrador y la configuración textual. En la novela, la escritura de José García, dilapida el orden falologocéntrico mediante la lógica del gasto y del goce, la cual tiene implicaciones textuales y en la subjetividad del narrador. Es de este modo que, la voz-escritura, motivada por un soplo corporal, se rebela contra el silencio, resultado de una hegemonía patriarcal.

El término de voz-escritura se deriva de la propuesta de écriture féminine de Cixous en la que vislumbra una escritura que se desplaza por los límites de la diferencia y lo irrepresentable, y no por un modelo de escritura exclusivamente femenino como se ha entendido a lo largo del tiempo. ${ }^{10} \mathrm{La}$ base de su enfoque es una inversión del razo-

años falsos de Josefina Vicens", presentada en la Universidad Autónoma Metropolitana en 2007 profundiza en ello. De igual modo, el texto "Josefina Vicens y El libro vacío: Sexo biográfico femenino y género masculino" de Ana Rosa Domenella, presente en Mujer y literatura mexicana y chicana (1990) de El Colegio de México resulta importante en dicha línea de investigación.

9 El artículo de Adriana Sáenz Valadez titulado "Masculinidad en El libro vacio y Los años falsos" publicado en 2019 por la Revista de Estudios de Género, La Ventana, de la Universidad de Guadalajara, propone una lectura de las novelas de Vicens desde el concepto "tecnologías de género" de la teórica italiana Teresa de Lauretis.

${ }^{10}$ Probablemente écriture féminine, al ser traducido primero al inglés como women's writing y al español posteriormente como "escritura femenina", se catalogó como un concepto que sugiere un tipo de escritura que pertenece exclusivamen- 
namiento del psicoanálisis freudiano a través del inter-dite ${ }^{11}$ y la desarticulación de los significantes entre las categorías de lo masculino y lo femenino. Según Aránzazu Hernández Piñero, la tarea de Cixous ha sido "pensar lo no pensable, desvelar el vínculo entre el logocentrismo y el falocentrismo, al tiempo que va iniciando esa otra historia, ese otro pensamiento que ella misma ha denominado el pensamiento de la diferencia sexual" (169). La obra de Cixous no es solo sobre la oposición sexual, también se extiende a visibilizar las disimilitudes, entendidas como grupos que difieren del sistema hegemónico.

Para Cixous, en Occidente por lo menos, la mujer ha sido trasladada al terreno de lo desconocido y lo irrepresentable en tanto que el lenguaje es incapaz de acercarse a lo que no es/está; funcionando de manera negativa, lo femenino es en la medida en que no es lo masculino. Así, lo femenino ha sido atribuido al enigma y lo desconocido. Cixous en "La joven nacida" apunta:

Viaje de la mujer: en calidad de cuerpo. Como si, separada del exterior donde se realizan los intercambios culturales, al margen de la escena social donde se libra la Historia, estuviera destinada a ser, en el reparto instituido por los hombres, la mitad no-social, no-política, no-humana de la estructura

te a la mujer y que inició una corriente de investigación que distingue rasgos femeninos en los textos, los cuales determinarían el género de la escritura. Sin embargo, Cixous, en su propuesta teórica, subraya que, para ella, escritores como Shakespeare, Kleist, Kafka o Joyce pueden ser leídos como práctica de una écriture féminine. Así, la escritura femenina no es exclusiva de un género, sino que, hablando en términos de Cixous, es aquella que permite la entrada a lo otro y que se contrapone al discurso falologocéntrico. De este modo, la propuesta de Cixous podría entenderse como una écriture féminine y no como una écriture des femmes.

${ }^{11}$ Luce Irigaray desarticula los argumentos de Freud desde el "entre-dicho", invierte la lógica freudiana partiendo de lo dicho y lo no dicho (Cardenal 355). El entre-dicho no agrega palabras o modifica los postulados, otorga otra connotación a los significantes freudianos. De este modo, respecto a la carencia de la que habla Freud al referirse a lo femenino, Irigaray piensa en un abismo abierto a posibilidades y no en un significado negativo. De este modo, interdite, lo "prohibido", se vuelve un comienzo. 
viviente, siempre la facción naturaleza por supuesto, a la escucha incansable de lo que ocurre en el interior, de su vientre, de su «casa». (18)

Si lo primero otro es la mujer y en extensión, lo femenino, y es llevado siempre hacia dentro, como un acto de aprisionamiento vigilado por la Ley del falologocentrismo, ${ }^{12}$ el cuerpo es entonces un medio de contención, incluso Cixous señala que la mujer: "no ha podido habitar su propia «casa», su propio cuerpo" (La risa de la medusa 20). El cuerpo de la mujer es "el cuerpo del delito", de lo incógnito, de la muerte y del vacío. ¿Dónde encuentra la posibilidad de subversión de tales categorías? En la escritura. Para Julieta Lopérgolo, "la escritura [en Cixous] es el lugar de la pregunta errante que no ansía sentido... Desafía lo inabordable, por artificioso del enigma, su escritura se ofrece como saber que se cifra en un devenir constante. No se escribe para definir al enigma, se escribe para darle paso a aquello que el lenguaje es incapaz de hacer pasar" (334). A propósito del estilo de Cixous, Marta Segarra señala que su escritura se sitúa entre diferentes géneros, buscando atravesar su porosidad, su prosa juega con los significantes, a la manera de la poesía y por consecuencia sus ensayos representan una complejidad teórica (79).

A comparación de otros estudios entre El libro vacio y Hélène Cixous, el objetivo de este artículo no es conceptualizar la obra de Vicens como escritura femenina en tanto que se introduce a esferas masculinas y se apropia de un lenguaje patriarcal; ${ }^{13}$ el foco de

${ }^{12}$ El término falologocentrismo o falolocéntrico se deriva del concepto de Jacques Derrida en La farmacia de Platón y es utilizado para referirse al privilegio masculino en la construcción simbólica a través de la supremacía de la escritura. De este modo, el falogocentrismo es la tendencia de situar lo masculino (falo) en el centro de cualquier discurso (Olivares 48).

${ }^{13}$ El texto de Ignacio Sánchez Prado llamado "La destrucción de la escritura viril y el ingreso de la mujer en el discurso literario: El libro vacío y Los recuerdos del porvenir" presenta a Josefina Vicens y a Elena Garro como escritoras que vivieron un complejo proceso de consagración, el cual se dio debido al registro de sus novelas y al tiempo en que surgieron, la década de los cincuenta y sesenta específicamente. 
interés es la escritura de José García y sus puntos de encuentro con una escritura femenina de acuerdo con sus implicaciones textuales y subjetivas, es decir, la noción de masculinidad y el paso a lo otro. ${ }^{14}$

\section{Del cuerpo al soplo: el anclaje corporal y la manifestación de la escritura}

La novela de Josefina Vicens narra la historia de José García y su intención de escribir una novela, que posteriormente será, en términos generales, un libro. De este modo, el relato se vuelve metaficcional y metaliterario a la vez, ya que el narrador-protagonista encara reflexiones en torno a su escritura, el proceso creativo y su vida como sujeto masculino. Se establece, en ese sentido, un espejo donde la obra en proceso es un reflejo de sí mismo. Los pasos que García establece para lograr su propósito son los siguientes: comprará dos cuadernos y en uno irá escribiendo sin filtro, para después, en el segundo, corregir lo anteriormente escrito. Sin embargo, a pesar de haber escrito en un el primer cuaderno sobre su vida, su pasado, su masculinidad, su relación con la feminidad, para él es un libro vacío.

La vida de José García transcurrió entre anhelos frustrados por sus circunstancias: "cuántos deseos no realizados sobreviven tenuemente en mí y aparecen de pronto, aunque amortiguados por la larga distancia" (Vicens 73). En algún momento quiso ser marino, pero tanto su madre como su padre se opusieron; de hecho, el principal impedimento fue que él era el varón de la familia. Es así que, desde ese momento, José García empezó a sentir el ser hombre y sus preceptos como una cárcel:

${ }^{14}$ Esto se halla en contraposición a textos como "El travestismo textual en Los años falsos" de Ute Seydel, "Una escritura desde el clóset: El libro vacioo" de Adriana González Mateos o "La bitextualidad en las novelas de Josefina Vicens" de Alessandra Luiselli, que especulan a través de los conceptos de la escritura femenina acerca de la sexualidad de la autora, su contexto histórico y político, y el uso de los seudónimos masculinos para el oficio de escritura. 
Mi padre, en cambio, pronunció un dramático discurso del que sólo pude entender que yo era el único hombre, la esperanza de su vejez y el protector de mis hermanas. Recuerdo que a medida que mi padre hablaba me invadía una especie de asfixia... Fue la primera vez que sentí el horror de estar encarcelado, condenado sin remedio. (Vicens 74)

José García establece un vínculo entre lo sensible del cuerpo y el silencio, un silencio que simboliza la incapacidad de actuar, la imposibilidad de decidir y también involucra el peso de ser hombre. El protagonista adopta una posición sumisa y acata las órdenes, lo cual se contrapone a la noción de masculinidad. En la oficina, con otros hombres, José García describe la rutina como otro ejemplo de la asfixia masculina: "A las dos de la tarde, agobiados por el encierro y el calor, todos tenemos una expresión de fatiga innoble, esencialmente física... Hay como un odio al cuerpo por tener que alimentarlo y vestirlo; hay un deseo violento — lo diré con la cruda palabra exacta - de que reviente de una vez. La obligación y la pobreza se enredan al cuello como una soga" (Vicens 71). El campo semántico que caracteriza a la oficina como espacio es la aversión, el mismo aborrecimiento que experimentó cuando escuchó a su padre decidir por él. Las obligaciones masculinas se encarnan en el cuerpo y lo transforman en una cárcel de la que José García no puede salir porque incluso él mismo encuentra en ella la seguridad de ser hombre. Su cuerpo destinado al trabajo es el último recurso que le queda para pensarse como hombre en tanto cumple con ese objetivo. La masculinidad para José García se instaura en la medida que se alcanza un fin, en este caso es el de un trabajador que mantiene a su familia.

El segundo rol en el que sus prácticas fijan la noción de masculinidad es la de padre. José García tiene dos hijos: el mayor, José; y el más pequeño, Lorenzo. El protagonista se pregunta cuál es su aportación hacia su hijo como hombre: "Papá... quiero hablar contigo... ¡ de hombre a hombre! ... ¡De hombre a hombre! ¿Qué supondrá mi hijo que es un hombre? Pienso que él piensa: el hombre lo es en el preciso momento en que tiene ya una mujer" (Vicens 
66). Sin embargo, José García no se conforma con esta definición y entonces encuentra la pregunta que ha acompañado su vida: ¿Qué es un hombre? ¿Quién soy yo? Ni la idea de padre ni la de esposo satisface la urgencia de su cuestionamiento: "Mi mujer empezaba a serme intolerable, mis hijos me irritaban; sentía yo a los tres como enemigos, como cadenas que me impedían todo movimiento" (Vicens 149).

Hasta ahora José García siente la masculinidad hegemónica ${ }^{15}$ como un yugo que día tras día pesa más, e incluso el cuerpo es campo de batalla entre la masculinidad vigorosa (representada en José y los hombres de su oficina) y su cuerpo atravesado por la vejez y la experiencia de los años. Después de tanto tiempo envuelto en la dinámica masculina sería obvio tener respuesta ante la pregunta de ¿qué es un hombre? José García podría responder que un hombre es el resultado de la experiencia o que la hombría es el legado en sus hijos. No obstante, es consciente de que los roles asociados a la masculinidad no pueden responder a una pregunta más profunda. Ni siquiera la idea de que el verdadero hombre es aquel que tiene muchas mujeres, pues para José García la relación extramarital que tuvo con Lupe Robles no satisfizo a la pregunta, en cambio le dio un remanso de tranquilidad ante la incógnita. Para el narrador, aunque los roles masculinos oprimen su cuerpo y sus anhelos, prefiere hasta cierto punto la seguridad que le brindan. Obedecer los acatos de la masculinidad es darle tranquilidad a un impulso que, con el paso del tiempo, ya no puede ignorar.

El episodio de su vida con Lupe es el regreso a la lógica falologocéntrica de la posesión y la dominación que sustenta a la masculinidad hegemónica: "yo tampoco la buscaba a ella, sino lo que representaba para mí: ... mi vanidad alimentada por la idea de que aún podía tener dos mujeres... mi última actuación en ese turbio

${ }^{15}$ El concepto fue acuñado por R.W. Connell en el texto Masculinities y es entendido como las pautas, mecanismos y procesos simbólicos por los que el patriarcado, relacionado con el género y prácticas masculinas, mantiene una jerarquía y dominación social y simbólica sobre los cuerpos con categoría femenina. 
mundo masculino de la conquista, la posesión y el alarde" (Vicens 147). El hombre José García es un papel que mantiene el control sobre otros y sobre sí mismo y, a su vez, es un lugar dónde protegerse del cuestionamiento que gana terreno dentro y fuera de su cuerpo: "Me aferraba a ella, pero en realidad me asía a todo aquello que pronto iba a desaparecer en mí ... era despedirme para siempre de esa vida anhelante, subterránea, violenta, torva, imprevista, ilegal y atractiva, con la que los hombres inferiores acreditamos nuestra virilidad" (Vicens 148). La relación que vincula a José y a Lupe no es de posesión, sino de comprobación del orgullo masculino; no es con relación a ella, sino consigo mismo. Tener una mujer no satisface un deseo carnal, remedia la incógnita sobre ser hombre.

Entonces, si el cuerpo de José García, en momentos es receptor de la dominación masculina, en la medida que la siente, la incógnita ante su estatuto de hombre también viene del cuerpo. La pregunta en este caso es la voz de un cuerpo que no se conforma con su realidad. El tema central de sus preocupaciones no es el hecho de situarse ante ese cuerpo viejo y que le produce enfado:

No me gusta mi cuerpo, es débil, blando, insignificante. No, no me gusta. Tal vez por eso nunca me ha importado y lo descuido. El resultado es que se impone siempre, en fracciones, en pequeñas o grandes molestias: dolor de muelas, gripes, arritmia, una serie de achaques. Pero, sobre todo, un temblor permanente, por dentro, un quebranto. Es como la seguridad de que algo va a ocurrir, el temor de que ocurra y la impaciencia de que ya ocurra. (Vicens 58)

La inquietud surge de los indicios que da su cuerpo en una especie de rebeldía, pues su cuerpo se hace notar a través del dolor físico, llama la atención mediante la incomodidad para que sea mirado. El cuerpo es la primera advertencia de la dominación masculina, el dolor renueva la relación entre el narrador y su corporalidad. Para José García, la nueva dimensión que su cuerpo adquiere tanto por la vejez como por ese denuedo extraño, le provoca un grado de incertidumbre cercana al temor. ¿Cómo podría el dolor, pensado como un torrente de energía, provenir de un cuerpo insignificante? 
La propuesta teórica de Cixous es usada para leer la experiencia de José García como un soplo. La autora contempla la escritura como un lugar de resistencia que se opone al falologocentrismo, pues la escritura implica una entrada al otro, ${ }^{16}$ lo cual subvierte la unidad fundamental del pensamiento hegemónico binario basado en dinámicas de dominación y posesión. La escritura para Cixous es entonces la posibilidad de incursionar en el orden más simbólico posible: el lenguaje. Y tomando en cuenta que el lenguaje ordena la realidad, quizá trastocándolo mediante la escritura es posible pensar en otro orden lingüístico, filosófico y social. Es necesario pasar por el soplo para llegar a esa escritura, el soplo implica una conquista del propio cuerpo para reapropiarse de sus significaciones.

El soplo no es un suceso natural para el falologocentrismo, pues este llamado tiene como propósito borrar las fronteras del cuerpo mediante la escritura. Cixous, en La llegada a la escritura, menciona: "¿Cómo no haber comprendido que un cuerpo es siempre sustancia de inscripción? Que la carne escribe y es dada a leer; y a escribir" (45). En José García hay una plena identificación entre el cuerpo y la escritura, un cuerpo que se pronuncia contra el estatismo de lo masculino, tal es la razón que, al empezar a escribir se suscitan experiencias corporales que a su parecer no tienen origen alguno: "El cuerpo, que me acompañaba con tanta cordialidad, empieza a independizarse... me duele la nuca y dentro de la cabeza siento como una espiral que rápidamente gira tratando de encontrar algo, ese algo que exprese algo" (99). Se puede observar que el cuerpo de José García redirige su autonomía, se separa del propósito masculino de la finalidad, y despliega una fuerza que no se alinea con la lógica de la posesión, sino del desprendimiento. El despojo del

${ }^{16}$ Aunque autores como Lacan, en Seminario 2 (presente en Miller), entendido como el orden simbólico ajeno a la singularidad personal o Levinas, en $L a$ huella del otro, como la representación que no puede ser neutralizada mediante un concepto, se han referido al Otro, me atengo al concepto de Cixous, entendido como el cuerpo de la diferencia sexual, el cuerpo de la mujer. Por consiguiente, y extendiendo su propuesta, con "el otro" me refiero a la alteridad. 
cuerpo provoca el temor del narrador-protagonista pues pone en crisis la dimensión identitaria y supone de igual modo la pérdida del control, José García ya no domina su cuerpo, las particularidades del quebranto corporal rebasan dicha relación.

Hélène Cixous, en La llegada a la escritura, al hablar del soplo menciona: "A veces pienso que empecé a escribir para dar lugar a la pregunta errante que me asedia el alma y me tritura y me taja el cuerpo; para darle suelo y tiempo; para desviar su filo de mi carne; un nuevo ser que no me ate, que no me expulse, que no perezca de estrechez" (18). Cixous parte de una escritura que tiene como base el cuerpo, y la pregunta exige su lugar, demanda su aparición en señales corporales; en el caso de José García, su cuerpo reacciona a la asfixia de su rol masculino. Si el falologocentrismo controla y posee, el cuerpo niega dicha subordinación. Es importante resaltar que el soplo es para Cixous el inicio de la ruptura con el orden establecido, porque el soplo rescata del silencio $^{17}$ a la diferencia, da lugar a una pregunta que no quiere ser respondida. Quiere visibilidad.

Para ejemplificar la ruptura de la masculinidad, que corresponde al mismo tiempo con la desapropiación del cuerpo, cabe mencionar que José García también la vive:

De pronto sentí algo, no sé exactamente qué. Era una especie de desdoblamiento: como si otro hombre se irguiera dentro de mí, se calzara unas botas duras, con clavos en la suela y empezara a caminar ... tratando de salir de algún lugar, para ir a otro determinado, aunque desconocido. (125)

El grado de saber del narrador, es deficiente en cuanto a su cuerpo y demuestra que el soplo adquiere formas inusitadas, deriva en un impulso de escribir pues el personaje más adelante anota: "alguien

${ }^{17} \mathrm{El}$ silencio es un término que Cixous utiliza para hacer referencia a la muerte como resultado del sistema hegemónico en La risa de la medusa. Sin embargo, el silencio también es lo irrepresentable y lo impensable. Por tal razón, el soplo busca dar lugar a la escritura y visibilizar lo que ha sido relegado simbólicamente en la historia (Cixous 26). 
dentro de mí quería decir algo, decía algo. Pero no entendí nada... podría simplificarlo y decir sencillamente: sentía yo una gran inquietud. Si lo dijera así lo comprenderían todos. Pero no era eso" (125). Se plantea entonces una enajenación entre sí mismo pues los dos hombres corresponden a dos yo, tal como si uno saliera de la crisálida de otro. El José García impulsado por el soplo se libera del José García vigilante de la masculinidad.

Cixous explica en La llegada a la escritura:

El soplo «quiere» una forma. «iEscríbeme!». Un día me suplica, un día me amenaza. «¿Vas a escribirme, sí o no?». Hubiera podido decirme: «Píntame!». Yo intentaba. Pero la índole de su furia exigía la forma que menos detiene, que menos encierra, el cuerpo sin marco, sin piel, sin muro, la carne que no se seca, que no se envara, que no coagula la sangre loca que quiere recorrerla — para siempre. «iDéjame pasar o lo rompo todo!». (22)

El soplo como torrente de energía que hierve en lo más profundo de José García pide un cuerpo que no restrinja, que no encuadre y no lo someta a la tiranía de la subyugación; pide a gritos habitar un cuerpo que fluya y que permita pensar un orden diferente, no jerarquizado. El cuerpo-cárcel que es el cuerpo masculino de José García se resiste a la escritura pues "escribir es trabajar; ser trabajado; (en) el entre, cuestionar... Recorrido multiplicador de miles de transformaciones" (Cixous 46). Escribir es rasgar y dejarse penetrar por lo otro. En la lógica falologocéntrica que opera en la masculinidad de José García, los fenómenos corporales y las ganas de escribir se sienten como una penetración que rompe todo a su paso, que confronta los paradigmas ya dados. Por ejemplo, la escritura cuestiona su pasado y su presente como hombre, lo lleva a imaginarse como un escritor sin familia, destruye sus certezas a nivel subjetivo. La escritura es el único camino para ordenar el caos que provoca hacerlo, pero se niega a ello. Ahí reside la paradoja de José García.

La feminidad simbólicamente es pensada desde la carencia y la masculinidad, desde la pérdida. Cixous, en La risa de la medusa, sos- 
tiene que: "El Imperio de lo Propio se erige a partir de un miedo típicamente masculino: miedo de la expropiación, de la separación” (37). José García siente vergüenza de sentir su cuerpo y posteriormente de escribir: "Yo no quiero escribir. Pero quiero notar que no escribo y quiero que los demás lo noten también. Que sea un dejar de hacerlo no un no hacerlo" (27). La resistencia entre dejar de escribir y no escribir implica callar ese soplo y dicho forcejeo acentúa la lucha entre las dos facetas de José García: un hombre que no quiere salirse de sus aristas y no quiere preguntarse, no quiere ser asaltado por la incógnita que inevitablemente lo llama a escribir.

Albergar en su cuerpo la interrogante lo hace sentir mal, pues él mismo siente su transformación, piensa que no ser un hombre resignado a su vida es estar corrompido por algo al compararse con un fruto que se pudre: "de haber llegado, cierto que, sin impurezas originales, a una especie de impureza final” (25). No obstante, puede existir una doble lectura al respecto: por un lado, podría ser una impureza originada por el arrepentimiento de ser únicamente un varón y haber desdeñado sus anhelos; o por el otro lado, una impureza que corrompe la masculinidad, en este caso, la escritura. El hecho de que existan estas dos opciones permite la posibilidad de pensar en la paradoja que implica para José García: ¿cómo acabar con el aliento que le muestra otra perspectiva pero que a su vez lo despoja de toda certeza?

Cuando José García por fin accede a encauzar sus ganas de escribir, empieza con lo siguiente:

No he querido. Me he resistido durante veinte años. Veinte años de oír: 'tienes que hacerlo..., tienes que hacerlo'. De oírlo de mí mismo. Pero no de ese yo que lo entiende y lo padece y lo rechaza. No; del otro, del subterráneo, de ese que fermenta en mí con un extraño hervor. (25)

Al observar todas las manifestaciones presentadas anteriormente: el desdoblamiento, la voz del cuerpo, la ruptura con el orden masculino establecido, se puede afirmar que censurar el cuerpo también sería censurar la palabra; de este modo, la escritura se caracteriza mediante el campo semántico de lo fluido, el cual no puede ser limi- 
tado o controlado. La escritura en Cixous, alineada a su propuesta de escritura femenina, es comparada con la tinta, la leche y la sangre como sustancias donadoras de vida a lo otro localizado en el campo de lo irrepresentable, y como un torrente que, al igual que el agua, la voz, y el grito, se desborda y quiebra los límites corporales y simbólicos. En el caso de José García pasa lo mismo:

Mi mano no termina en los dedos: la vida, la circulación, la sangre, se prolongan hasta el punto de mi pluma. En la frente siento un golpe caliente y acompasado. Por todo el cuerpo, desde que me preparo para escribir, se me esparce una alegría urgente. Me pertenezco todo, me uso todo; no hay un átomo de mí que no esté conmigo, sabiendo, sintiendo la inminencia de la primera palabra. (98)

Cixous al hablar de la obra de Clarice Lispector" en "Vivir la naranja" expone: "necesitamos que una voz húmeda nos llame para que nuestra alma deje de morir de sed en nuestra garganta" (128). La escritura es para José García la misma sustancia viva que circula en su cuerpo, las palabras son la sangre, la voz y el grito contra la muerte. Si la vejez y su resignación con respecto a la masculinidad

${ }^{18}$ La relación ya ha sido establecida por Cixous; sin embargo, su interpretación de Lispector como ejemplo de escritura femenina es a partir de su obra completa, no de un texto en particular. No obstante, es conveniente establecer un vínculo entre El libro vacio y La hora de la estrella, pues ambas novelas exploran el proceso de escritura. En Vicens con José García y en Lispector con Rodrigo S.M., la escritura es un proceso y lugar para dos sujetos que cuestionan existencialmente su lugar en el mundo pero que llegan al papel y a la tinta por ser la alteridad que desea un espacio. Aunque las dos novelas poseen una corta extensión, mecanismos como la multiplicidad de títulos en Lispector y la metaficción en Vicens muestran la vocación de ensanchamiento y devenir mediante la escritura. Seguir escribiendo argumentos sin finalidad, la historia de José García y de Macabea respectivamente, es una apropiación de la escritura emancipada del orden hegemónico pues no solo ambos personajes comparten la pobreza y la miseria, sino también la insatisfacción de ser ellos mismos. Cixous en La hora de la estrella dice: "Macabea es un mar de preguntas que no pide respuesta: pide la vida" (163). 
son la muerte, la escritura es la reanimación, la escritura es el torrente que desborda: "Sentí que debía decir todo esto y lo dije, atropelladamente, a borbotones, trémulo de emoción. A medida que hablaba experimentaba la sensación de que por fin había encontrado el camino; sentía que era yo mismo, pero al mismo tiempo otro; otro que me reconciliaba conmigo mismo y me libertaba" (Vicens 82). Si José García presiente la corriente de la escritura en su cuerpo que está a punto de desbordarse, entonces decide saciarla y de pronto se oye decir a sí mismo: “Escríbeme!”. Su escritura no comprende de límites ni de planes, es extracto de su cuerpo y por lo tanto también tiene implicaciones en la configuración textual mediante la lógica del gasto y del goce, las cuales derriban la lógica falologocéntrica. ${ }^{19}$ Dichas implicaciones serán tratadas en los apartados siguientes. Tal es la razón por la que José García compara el no escribir con secarse, como si secarse fuera la metáfora para hablar tanto de su vejez como de su rechazo a la escritura, su miedo a dejar de ser:

Como un ladrón, le robo una gota a mi seca convicción de no escribir; esa gota última que queda siempre cuando la resequedad acontece de afuera hacia dentro... Quiero decir: cuando uno no se seca por sí mismo sino por uno mismo. Secarse por sí mismo es carecer del elemento que humedece y conserva la escritura. Y secarse por uno mismo es hacer desaparecer voluntariamente ese elemento, extraerlo de uno para provocar la resequedad. En el primer caso nunca queda esa gota última; en el otro queda siempre, escondida, traicionando el propósito, lista para brotar. (Vicens 49)

Es notorio que José García admite el torrente de escritura, el cual se encuentra paralizado por sí mismo, no se ha secado el impulso de

19 Entendida como una dinámica que privilegia la connotación simbólica masculina, la cual limita a los cuerpos mediante razonamientos binarios, limitados y restringidos para identidades que simbólicamente se salen de las condiciones patriarcales. Quienes son lo Otro son apartados a lo irrepresentable. 
escribir, no carece de él; José García ha contenido su escritura para no traicionar su masculinidad, escribir representa alejarse de dicha finalidad y explorar un lugar nuevo y sin rutas marcadas socialmente.

\section{El escape de lo simbólico femenino mediante el derrama- miento de la voz-escritura}

Tal como se explicó al principio del primer apartado, el plan que José García establece para escribir es el siguiente: compra dos cuadernos, en el primero irá escribiendo para después "pasarlo al número dos, ya cernido y definitivo" (Vicens 29). Además, se propone escribir al principio una novela: "Mi propósito, al principio, era escribir una novela. Crear personajes, ponerles nombre y edad, antepasados, profesión, aficiones" (44). Sin embargo, sus planes no salen como lo estipuló. Tal es la razón por la que, cuando su hijo José irrumpe en su cuarto y le pregunta si está escribiendo una novela entra en un estado de cólera y dice: " ¡No soy escritor! No lo soy; esto que ves aquí, este cuaderno lleno de palabras y borrones no es más que el nulo resultado de una desesperante tiranía que viene de no sé dónde" (54). La escritura como resistencia se configura a través de la oposición entre sus deseos de escribir una novela, posteriormente un libro, que comunique algo, y que por supuesto no se trate de sí mismo porque José García se ha puesto esta condición: "NO ESCRIBIR EN PRIMERA PERSONA [sic] . . . No usar la voz íntima, sino el gran rumor" (Vicens 42); sin embargo, la aversión que tiene a hablar de sí mismo corresponde a la inquina que le provoca hacer caso de la voz del cuerpo. La voz del cuerpo implica hablar de sus sensaciones, de su identidad, de sus anhelos y también de su familia. ¿Cómo hablar de todo aquello que evita a toda costa?

El narrar una historia, desde la perspectiva de José García, comprende la posesión: "la única forma de apoderarnos hondamente de los seres y de las cosas y de los ambientes que usamos es volviendo a ellos por el recuerdo, o inventándolos o darles un nombre" (32). En la noción de escritura que posee García se replicaría la maquinaria del falologocentrismo, donde se posee el lenguaje para un fin, pero 
José García no puede tener el lenguaje, no puede capturar a la voz, sino ser guiado por ella: “¿Cómo le harán los que escriben? ¿Cómo lograrán que sus palabras los obedezcan? Las mías van por donde quieren, por donde pueden. Cuando ya las veo escritas, cuando con una vergüenza golosa las releo, me dan pena. Siento que van desprendiéndose de mí y cayendo en mi cuaderno. Cayendo solamente, sin forma, sin premeditada colocación" (Vicens 69). Hélène Cixous, cuando se cuestiona en dónde reside la diferencia en la escritura femenina, regresa al razonamiento del psicoanálisis e invierte los códigos simbólicos que caracterizan al goce femenino. ${ }^{20}$ En ese sentido, según el falologocentrismo, la mujer en tanto cuerpo carente y destinado al abismo, entendido como el terreno de lo irrepresentable, disfruta y establece una dinámica de goce diferente a la de lo Propio masculino. La relación del don femenino se vincula con el gasto, pues lo femenino da sin retribución; mientras que el don masculino se asocia a la reserva, pues todo lo que entrega requiere una subvención, es decir, una retribución material o simbólica. Carencia y gasto como economía femenina se contraponen a la masculina, por lo tanto, el goce derivado de dicha dinámica responde a una economía no hegemónica. Cixous señala: “Podemos hablar de otro gasto? Realmente, no hay don «gratuito». Nunca se da a cambio de nada. Pero toda la diferencia radica en el porqué y en el cómo del don, en los valores que el gesto de dar afirma, hace circular; en el tipo de beneficio que obtiene el donante del don, y el uso que hace de él” (47). Para José García, la escritura, vista como palabras y voz, que no apoyan el deseo de reconocimiento masculino, se ven como una pérdida y como un gasto innecesario. Constantemente se pregunta ¿a dónde va este texto? Sin embargo, es importante darse

${ }^{20}$ Cixous menciona que hay una economía masculina que siempre se ve amenazada por lo no-propio. El ser masculino se ve amagado por perder-se. Su gasto se convierte en un don-que-recibe. El don es rentable y la pérdida se transforma en ganancia. Lo femenino está vinculado con la "desapropiación”, da sin límites. En este punto se inserta el goce femenino que adora el cuestionamiento, pues simbólicamente establece una economía desde el vacío. Paradójicamente dicha exigüidad no interfiere con la circulación del don (35). 
cuenta que las palabras que elige para hablar de la vergüenza y de la ineficacia de su escrito, competen al campo semántico de la fruición: "Pero el caso es que jamás conocerá mi cuaderno, ni el gozo y el dolor con que inexorablemente escribo" (183).

La pérdida de sentido, de palabras y de propósito se convierte en un estado temporal adecuado para el deleite. Saberse como un hombre no tradicional y carecer de un propósito masculino retribuyen a José García de un placer inusitado e incluso morboso. Caminar por el abismo de lo prohibido le asusta, pero lo satisface, por tal motivo los cuadernos son objetos clandestinos, porque invierten los valores tradicionales del varón de una sola arista. Si escribir es abrir paso a la pregunta que no quiere respuesta, la cual se deleita de lo que no se puede poseer, entonces es una práctica digna de esconderse. Por eso José García se recluye en un cuarto, para ocultar que escribe un texto que poco a poco se le ha salido de las manos, es decir, que no ha podido poseer ni controlar. Cixous dice en torno al gasto femenino:

¿Cómo da ella? . . Ella también da para. Al darse, se da: placer, felicidad, valor añadido, imagen sublimada de sí misma. Pero no intenta «hacerlo constar en sus gastos». Puede no recuperarlo, no jactándose nunca, derramándose, yendo por todas partes hacia el otro. No rehúye al extremo; no es el serdel-fin (de la finalidad), sino del alcance. Si existe algo de la mujer es, paradójicamente, su capacidad para des-apropiarse sin egoísmo: cuerpo sin fin, sin «extremidad», sin «partes» principales. (48)

La dinámica de la escritura preconcebida por García conlleva dos vertientes: por un lado, quiere lograr, al principio, un relato y después, de manera ambigua, un libro, para conseguir la admiración tanto de su familia como de los demás. Cixous, en La risa de la medusa, al puntualizar la dinámica falologocéntrica en la masculinidad menciona: "Un hombre siempre es puesto a prueba, es preciso que se «muestre», que demuestre su superioridad a los demás. La ganancia masculina casi siempre se confunde con un éxito socialmente 
definido" (48). Así, la culminación del libro es la culminación de su objetivo: ser reconocido como un escritor, eso supondría su salida de ser un simple oficinista. El ser escritor demostraría, tanto a él como a los demás, una apropiación de sí mismo, por consiguiente, confirmaría su propósito de hombre y así acallaría a la pregunta errante. Afirmar la imagen masculina supondría lograr un texto domado que correspondiera con el orden establecido, que se alineara a la noción de la masculinidad como admiración de otros: "Mi esfuerzo en lo sucesivo, debe ser aplicarse únicamente a vender el anhelo de ser leído, de ver mi nombre escrito en cada página, de oír a la gente decir: "el libro de José García”' (Vicens 181).

Sin embargo, el derramamiento, expresión del soplo de un cuerpo sin límites, tiene implicaciones textuales. Para José García, el modelo de escritura que lleva a cabo es incomprensible porque no tiene un inicio marcado y menos un final. Es un texto que rompe la causalidad, pues la secuencia narrativa y el orden del discurso se diluyen mediante el tiempo subjetivo, es decir, recuerdos, ensoñaciones y comentarios sobre su propio texto. Si el propósito de José García era escribir una novela, las categorías aristotélicas de acción, tiempo y lugar se ven comprometidas. Es un texto que, para el narrador, derrocha el tiempo y la palabra. El cuaderno número uno del narrador-protagonista se asemeja al derramamiento del soplo y de la voz-escritura tal como lo describe Cixous:

¡Voz! Es también lanzarse, ese desparramamiento del que nada vuelve. Exclamación, grito, ahogo, aullido, tos, vómito, música... Así escribe como se lanza la voz, hacia adelante, en el vacío. Se aleja, avanza, no vuelve sobre sus pasos para examinarlos. No se mira. Carrera peligrosa. Al contrario del narcisismo masculino, preocupado por afirmar su imagen, por ser mirado, por verse, por juntar sus fragmentos, por embolsárselos. (La risa de la medusa 57)

De igual modo, se pueden establecer dos correspondencias con el tipo de escritura que propone Cixous, pues ella señala que ese derramamiento de la voz-escritura "no se produce sin un gasto de 
sentido, de tiempo y de orientación" (La risa de la medusa 47). La pérdida de José García radica en el modo de perder la admiración de otros y de perder el tiempo escribiendo un texto-cuerpo deshilvanado. Y esta pérdida de sentido en el texto es también la pérdida de sentido de su masculinidad. Hay que recordar que José García se recrimina el gastar su tiempo, pues no solo se enfrenta a la hoja en blanco como metáfora de la imposibilidad de escribir, sino que también la hoja en blanco es un detonador que incita una introspección, por tal razón, concluye que debería ser una actividad vedada para sujetos como él que no saben ser hombre. En La llegada a la escritura, Cixous menciona que: "¿Acaso la escritura no era el lugar de lo Verdadero? ¿Acaso lo Verdadero no es claro, distinto y uno? Y yo imprecisa, varias, simultánea, impura. ¡Renuncia!” (49). La unidad masculina en José García también se ve comprometida, reconoce la inconsistencia entre lo que es y lo que lo representa. La escritura es entonces el espacio donde la diferencia puede contraponerse a la hegemonía, la escritura es el arma contra el silencio de lo irrepresentable. Por tal razón, la pregunta no quiere imponerse a través de la búsqueda de la respuesta, quiere un lugar, y ese lugar es visible mediante la escritura como aullido de emancipación del orden hegemónico.

Conforme el texto avanza, más intrincado se vuelve y la invasión del tiempo subjetivo se contrapone al tiempo objetivo, no existen indicios que den al lector señales de ubicación espacio temporal. José García vuelve a sus recuerdos, a manera de caja china, los cuales se mezclan con sus brotes de imaginación. Las fronteras espacio-temporales se diluyen y reconoce que su idea de libro ya no es la misma:

¿Creo todavía en el libro? Me lo pregunto muchas veces... ¿Cómo voy a ordenarlo? Además, hasta el momento no he hecho más que hablar de mí mismo, que fue justamente lo que al principio declaré que quería evitar. Ahora comprendo que no tenía la menor idea de mis verdaderas posibilidades. (177) 
¿Qué significa perder el tiempo para José García? Desde la lógica masculina significa perder-se derrochar su energía, desperdiciar su vida, dilapidar su constitución de hombre, pues en José García la escritura posibilita lo impensable: "mi deseo sigue inmóvil... por eso, el concepto de imposible ha llegado a ser el único que entiendo y el único que no entiendo" (Vicens 92). El prolongar y extender el tiempo subjetivo podría simbolizar la renuncia al tiempo objetivo marcado por los estatutos masculinos hegemónicos. Por eso, cuando su esposa le dice que pierde el tiempo al encerrarse en su cuarto a escribir, en realidad José García invierte tal lógica: mediante la de la voz-escritura y su mecánica del derrame, el tiempo subjetivo conquista al tiempo objetivo y crea un espacio de resistencia:

Siento como un golpe en el pecho. De pronto todo se ordena en mi mente. No, ya no se me va a hacer tarde nunca. Soy dueño de mi tiempo, soy mi propio dueño. Me levantaré y sólo tendré que caminar unos pasos y sentarme ante la mesa donde me esperan doce cuadernos nuevos... Soy un hombre libre, un hombre sin reloj, sin calendario, sin medida. Puedo hacer lo que quiera. (201)

Como consecuencia, José García se piensa desde la lógica del no límite que tiene impacto en su escritura. Si el texto es carne y cuerpo, entonces se vislumbra un constante devenir en la escritura, un alargamiento del lugar donde el narrador-protagonista encuentra al derrame de la palabra, del tiempo, en contra de la muerte que enmudece al cuerpo y recorta los minutos: 'Y si no puedes dejar de escribir, continúa haciéndolo en este cuaderno y luego en otro, y en otro, siempre secretamente, hasta el día de tu muerte" (Vicens 179).

Otro ejemplo donde la escritura vence al tiempo objetivo sucede cuando José García, en su último intento de no ceder a la escritura, establece un periodo de seis meses donde no escribirá; sin embargo, no puede dejarlo: "Mañana empezarán a correr los seis meses. Total, un día más o menos no tiene importancia” (130). Y de nuevo encuentra en su propia prohibición el goce de la palabra y lo escrito, el alargamiento que permite esta operación: 
Durante todo ese tiempo, ni siquiera los abriré, para no caer en la tentación de escribir. Si acaso, algunas noches podré releerlos un poco, cambiar algunas palabras, si encuentro muchas repeticiones, y, sobre todo, revisar la ortografía, que siempre me ha preocupado. (131)

Al final del libro, José García se permite fantasear con transformarse en el héroe que siempre soñó, a pesar de que ya ha perdido tanto su tiempo como su juventud, pero esto es posible mediante el descubrimiento de su escritura como un grito contra el vacío, contra la muerte y el silencio de lo masculino donde divisa un nuevo orden, donde la imposición no gobierna. Su escritura grita: "Me voy. Soy libre" (199), pero también cuando percibe que su voz, trenzada con la escritura, es el arma contra la afonización. Tal cosa es el llamado a la escritura:

Estoy diciendo sencillamente, con la misma falta de sentido y de objetivo, pero con el mismo incontrolable impulso y el deleite con los que un niño se asoma al brocal de un hondo pozo, grita su nombre y escucha emocionado que aquella misteriosa oquedad lo repite. No lo grita para alguien, lo repite alguien; lo grita él mismo, lo escucha él mismo, pero su nombre ha sido lanzado a una profundidad de la que regresa con un tono solemne, telúrico, y tan distinto de aquel en que fue pronunciado, que te hace pensar no en que es un eco, sino una respuesta o un llamado sobrenatural. (Vicens 190)

Para terminar y advertir que José García descubrió las posibilidades de la escritura como espacio de resistencia a la masculinidad hegemónica predominante, pasa del no quiero escribir al sí quiero escribir. Cixous en La risa de la medusa escribe: "lo femenino (los poetas lo sospecharon) afirma: ... . and yes I said yes I will Yes. Y sí, dice Molly, arrastrando a Ulysse [sic] más allá de todos los libros hacia la nueva escritura, he dicho sí, quiero Sî” (45). José García pasa del resistirse al impulso, a lo siguiente: "tengo que encontrar esa primera frase. Tengo que encontrarla” (219). Aunque es el final de la novela, 
establece que José García ha admitido lo otro en la escritura, lo otro es sí mismo, el hombre que quiere ser libre y encuentra en la voz de su cuerpo, en el impulso, el llamado a la escritura en un cuerpo que no impuso un orden. Es notorio que el devenir de su cuerpo es el texto, que, aunque le digan que debería comportarse como un hombre de su edad y esperar la muerte, su cuerpo responderá: no me acabo, no me seco, tengo sed, no me muero.

\section{Conclusión}

La novela de Josefina Vicens propone una masculinidad que no está supeditada por los alcances del falo y, en ese tenor, plantea un modelo masculino que podría renovar su relación con el cuerpo y el lenguaje. En tanto que el cuerpo es texto y viceversa, la novela en proceso de José García es sí mismo, el reto de pensar-se y habitar espacios que durante los siglos fueron pertenecientes a aquellos individuos que representaban la ruptura de uno de los binomios metafísicos más importantes de la humanidad: lo masculino y lo femenino. El personaje de José García y sus prácticas de escritura asientan un modelo novedoso para las masculinidades de la literatura mexicana y, por si fuera poco, demuestra que la resistencia puede habitarse por hombres y mujeres no categorizados estrictamente por sus cuerpos. Josefina Vicens creó a un personaje que habitó categorías que para la lógica patriarcal son irreconciliables y que posibilitó la existencia de otros y otras personajes no binarios en la literatura mexicana actual. Si la escritura de ciertos narradores puede desbordar cánones y moldes hoy en día, es porque de repente José García decidió escribir un día a pesar de las cadenas, los grilletes y el vacío del papel en blanco. Y porque Josefina Vicens escribió una novela urbana, novedosa y desafiante para un México que todavía era de cierto modo rural y postrevolucionario.

Aunque la presente investigación tiene como objetivo establecer un diálogo entre los ensayos de Cixous sobre la escritura, sería interesante extender este marco teórico a la segunda novela de Vicens, Los años falsos, pues también el protagonista, Luis Alfonso, vive 
muy de cerca la masculinidad hegemónica proveniente de su padre fallecido y el entorno en el que crece. De igual modo, la escritura juega un papel muy importante, por lo que podría desencadenar en nuevos vínculos entre la escritura pensada desde el feminismo de la diferencia y las expresiones de las masculinidades dominantes. Es importante mencionar que, tomar los textos de Cixous como marco teórico es un reto metodológico, pues además de que su prosa se aleja de las convenciones académicas y filosóficas, ella misma se niega a pensar sus ensayos como teoría filosófica o literaria. Por tal razón son casi inexistentes las pautas para replicar o ampliar sus interpretaciones a diferentes textos literarios.

Las corrientes más actuales de análisis semiótico ${ }^{21}$ establecen puentes que renuevan las perspectivas de la literatura mexicana del siglo XX, especialmente cuando se trata de las escritoras de medio siglo, tales como Josefina Vicens, Inés Arredondo, Luisa Josefina Hernández, María Luisa Puga o Guadalupe Dueñas.

\section{Bibliografía}

Cano, Gabriela. "Josefina Vicens, una voluntad de autonomía". Castro y Petterson, pp. 29-37.

Cardenal Orta, Tatiana. "Ese cuerpo que no es uno. La sexualidad femenina en Luce Irigaray". Thémata. Revista de filosofía, no. 46, 2012, pp. 353-360.

${ }^{21}$ Podrían establecerse puentes que dialoguen entre la teoría de los afectos y las sensaciones de la escritura en Cixous considerando que, en las novelas de Vicens tienen un sustrato corporal que ilumina áreas desconocidas del cuerpo en relación con la pluma y la tinta. Elspeth Probyn y su propuesta sobre la writing shame es una vía para analizar la escritura de José García, pues hay un constante ocultamiento de su vocación literaria, la cual al mismo tiempo tiene implicaciones con el cuerpo y las emociones, temas relevantes para la construcción de nuevas masculinidades. Por último, se podría proponer una investigación donde se analice a José García desde los estudios de la vejez y sus vínculos con la construcción de los espacios y los objetos. 
Castro, Maricruz y Aline Petterson, editoras. Josefina Vicens. Un vacio siempre lleno. $1^{\mathrm{a}}$ ed., Instituto Tecnológico y de Estudios Superiores de Monterrey, Campus Toluca / Fondo Nacional para la Cultura y las Artes, 2006.

Cixous, Hélène. "La joven nacida". La risa de la medusa. Ensayos sobre la escritura, $1^{\mathrm{a}}$ ed., prólogo y traducción de Ana María Moix, traducción revisada por Myriam Díaz-Diocaretz, Anthropos / Comunidad de Madrid / Consejería de Educación / Dirección General de la Mujer / Universidad de Puerto Rico, 1995, pp. 11-108.

- La llegada a la escritura. $1^{\text {a }}$ ed., traducción de Irene Agoff, Amorrortu, 2006.

- "Vivir la naranja". La risa de la medusa. Ensayos sobre la escritura, pp. 109-157.

Connell, R.W. "Four Studies of the Dynamic of Masculinities. Masculinities, University of California, 2005, pp. 87-182.

Domenella, Ana Rosa. "Josefina Vicens y El libro vacio: sexo biográfico femenino y género masculino". Mujer y literatura mexicana y chicana: culturas en contacto, El Colegio de México / El Colegio de la Frontera Norte, 1990, pp. 175-180.

Domenella, Ana Rosa y Norma Lojero, coordinadoras. Josefina $V_{i}$ cens: Un clásico por descubrir. $1^{\mathrm{a}}$ ed., Universidad Autónoma Metropolitana, 2017.

González Mateos, Adriana. "Josefina rebautizada". Castro y Petterson, pp. 37-57.

Gordon Listokin, Samuel. "Nota preliminar". Josefina Vicens: Un clásico por descubrir, $1^{\mathrm{a}}$ ed., coordinado por Ana Rosa Domenella y Norma Lojero, Universidad Autónoma Metropolitana, 2017, pp. 11-12.

Hernández Piñero. "Hélène Cixous: la escritura como deseo de alteridad”. Lectora, no. 17, 2011, pp. 167-180.

Levinas, Emmanuel. La buella del otro. Traducción de Esther Cohen, Silvana Rabinovich y Manrico Montero, Taurus, 2000.

Lincoln Strange Reséndiz, Isabel. "La masculinidad como producción discursiva y la feminidad como silencio en El libro vacio y Los 
años falsos de Josefina Vicens”. 2017. Universidad Autónoma Metropolitana, Tesis de maestría, dirigida por Ana Rosa Domenella. Lopérgolo, Julieta. "Cuerpo, feminidad y escritura en La llegada a la escritura, de Hélène Cixous. Otra relación posible entre género y psicoanálisis". VI Congreso Internacional de Investigación y Práctica Profesional en Psicología XXI Jornadas de Investigación Décimo Encuentro de Investigadores en Psicología del MERCOSUR. Facultad de Psicología / Universidad de Buenos Aires, www.aacademica. org/000-035/663

Luiselli, Alessandra. "La bitextualidad en las novelas de Josefina Vicens". Revista de humanidades: Tecnológico de Monterrey, no. 2, 1997, pp. 19-36.

Martínez Rodríguez, Ana Josefina. "Narrador equisciente. La mujer objeto. El libro vacio y Los años falsos de Josefina Vicens". Lado sur: narrativa y poética latinoamericana de finales de siglo XX y principios del siglo XXI (Ensayos 2004-2019), Canto Rodado, 2019, pp. 117-124.

Medina Cervantes, Víctor Manuel. "Mirar con la palabra. Josefina Vicens: escritora de cine”. Domenella y Lojero, pp. 269-281.

Miller, Jacques Alain. El seminario de Jacques Lacan. Libro 2. Paidós, 1993.

Mosqueda Rivera, Raquel. "Josefina Vicens: el derecho al silencio". Doscientos años de narrativa mexicana: siglo XX, editado por Rafael Olea Franco, El Colegio de México, 2010, pp. 201-220.

Olivares, Cecilia. "Falogocentrismo". Glosario de términos de crítica literaria femenina, El Colegio de México, 1997, pp. 48-52.

Palazón Mayoral, María Rosa. "No soy nadie: Josefina Vicens. Los perros de Dios". Domenella y Lojero, pp. 255-269.

Petterson, Aline. "Las pasiones de Josefina Vicens". Castro y Petterson, pp. 21-28.

Pollack, Sara. "La nada y sus contextos. La ausencia en la obra de Josefina Vicens". Revista de estudios hispánicos, vol. 45, no. 3, 2011, pp. 615-634.

Sáenz Valadez, Adriana. "Masculinidad en El libro vacio y Los años falsos de Josefina Vicens". Revista de estudios de género. La Ventana, vol. 6, no. 49, 2019, pp. 114-142. 
Sánchez Prado, Ignacio. "La destrucción de la escritura viril y el ingreso de la mujer al discurso literario: El libro vacio y Los recuerdos del porvenir". Revista de crítica literaria latinoamericana, año. 32, no. 63, 2006, pp. 149-167.

Segarra, Marta. "Vida y verdad: Autobiografías de Hélène Cixous". Signa, no. 27, 2018, pp. 75-91.

Seydel, Ute. "El travestismo textual en Los años falsos". Castro y Petterson, pp. 123-137.

Tornero, Angélica. "Existencialismo y literatura. El libro vacío de Josefina Vicens". Hispanic Journal, vol. 35, no. 1, 2014, pp. 125-139. Vicens, Josefina. El libro vacio y Los años falsos. $1^{\text {a }}$ ed., prólogo de Aline Petterson, Fondo de Cultura Económica, 2006. 